\title{
The Transforming Cultural Identity of Hong Kong as Reflected in Jackie Chan's Police Story Series
}

\author{
Zhuang Qing ${ }^{1}$, Li Yueming ${ }^{2, *}$ \\ ${ }^{1}$ Faculty of English Language and Culture, Guangdong University of Foreign Studies, Guangzhou, China \\ ${ }^{2}$ School of Foreign Languages, Guangdong Pharmaceutical University, Guangzhou, China
}

Email address:

qzhuang@foxmail.com (Zhuang Qing), yueming.lee@163.com (Li Yueming)

${ }^{*}$ Corresponding author

\section{To cite this article:}

Zhuang Qing, Li Yueming. The Transforming Cultural Identity of Hong Kong as Reflected in Jackie Chan's Police Story Series. English Language, Literature \& Culture. Vol. 5, No. 4, 2020, pp. 159-164. doi: 10.11648/j.ellc.20200504.16

Received: November 30, 2020; Accepted: December 11, 2020; Published: December 22, 2020

\begin{abstract}
Filmic texts embody the discussion of issues like identity and self-determination. Many films of Jackie Chan who is a well-known international film star, set the story in Hong Kong, thus inevitably presenting various cultural aspects of the city. Being an especially important historical event, the return of Hong Kong to China affects every aspect of people's lives, which are consciously or unconsciously recorded in filmic texts. Seeking recourse to Stuart Hall's concept of cultural identity and Wang Yuechuan's theory of identity recognition, this paper analyzes Jackie Chan's three filmic texts from the Police Story series, hoping to probe into the conflicts and changes of Hong Kong's transforming cultural identity at three time periods before and after the establishment of the Hong Kong Special Administrative Region upon the reunification with China, so as to prove both the complexity and importance of the identity issues. The paper will approach the three filmic texts from the following aspects: changed names of the main characters and their symbolic meanings, differences in plot and dialogue designs, and cultural meaning of urban space and architecture. Finally, the paper also invites the readers to reflect on the issues of representation on differences and identity recognition in general.
\end{abstract}

Keywords: Cultural Identity, Hong Kong, Jackie Chan, Police Story Series

\section{Introduction}

Cultural identity is quite an important issue in postcolonial studies [1]. It is a sense of belonging to a group that reaffirms itself, consisting of values, customs, meanings and beliefs. Lots of research have been done over the issue of cultural identity, breaking through the traditional boundaries of various disciplines [2]. As for Hong Kong, a once-colonized Chinese city by the UK for 99 years, cultural identity becomes an unavoidable topic. It is evolving with constant confusion of her citizens, and is confused with constant evolution. According to International Herald Leader, a newspaper, over 200,000 Hong Kong people had applied for British National Overseas passport (BNO) before the reunification of Hong Kong with China in 1997, whereas up till 2007, about $60 \%$ of the Hong Kong people had applied for HKSAR passport (Hong Kong Special Administrative Region passport) [3]. It is obvious that the cultural identity of Hong Kong is changing.
Among the complicated external forces to form the cultural identity of Hong Kong, the influence from cultural media is not to be ignored. As Hong Kong's cheeky, lovable and best known film star, Jackie Chan has established international success in cinema industry both home and abroad (namely, Hollywood) [4]. Being an actor from Hong Kong, he can be regarded as a cultural symbol of the city. Therefore, lots of his filmic products can be employed to analyze and decode the cultural identity of Hong Kong, especially the five films of the Police Stories series. They span from the year 1985 to 2004, not only molding a heroic image of the protagonist but also providing a base for analyzing the conflicts and anxieties out of the changing cultural identity. The thesis will focus on three filmic texts-Police Story (1985), Police Story III: Super Cop (1992), and New Police Story (2004), for the years of production are symbolic. The year 1985 was right after the signing of the Chinese-British joint declaration on the question of Hong Kong in December, 1984; the year 1992 was the first year of Britain's last governorship in Hong Kong 
(Governor Chris Patten, 1992-1997); the year 2004 was the $7^{\text {th }}$ year after the reunification of Hong Kong with China. These are crucial moments of the changing cultural identity of Hong Kong. Just as what Mercer has argued, "identity is hotly debated when it is in crisis" [5].

Stuart Hall points out that there are at least two ways of thinking about cultural identity. The first position defines cultural identity in terms of "one, shared culture, a sort of collective 'one true self', hiding inside the many other, more superficial or artificially imposed 'selves', which people with a shared history and ancestry hold in common" [6]. $\mathrm{He}$ continues to argue that there is a related but different position, where cultural identity is a matter of "becoming as well as of being", which "belongs to the future as much as to the past. It is not something which already exists, transcending place, time, history and culture" [6]. Based on the second position, the thesis intends to better interpret Jackie Chan's films and better understand the conflicting and transforming cultural identity of Hong Kong from the following aspects: changed names of the characters, the plot of the films and conversations between the characters, urban space and architecture, and reflection on representation on differences and identity recognition.

\section{Changed Names of the Characters}

Name is an essential part of one's identity and a meaningful symbol. To the Chinese, the significance and power of name is tremendous [7]. In filmic texts names of characters are usually endowed with more significance. In the first four out of five Police Story series by Jackie Chan, the protagonist (acted by Jackie Chan) is named Chan Ka-Kui, while in the $5^{\text {th }}$ one, Chan Kwok-Wing. Ka-Kui means a horse belonging to a single family; Kwok-Wing, national honor. Metaphorically the change of the names here reflects the transforming identity of policeman in Hong Kong. The first one implies that the police are simply working and dying for the British Empire, whereas the second one signifies that the police are maintaining social stability for a more prosperous motherland. Indeed, in Police Story (1985), the orphaned Ka-Kui almost trades his life for a peaceful society but gets no understanding or sympathy. A scene shows that the wronged Ka-Kui goes back to the police station but to see that his immediate superior wants to arrest him based on superficial evidences. Filled with anger, he roars: "when we are battling with the enemy, he only cares about whom he's going to dine with. When we risk our lives to bring back the bad guy, he only cares about the so-called procedure... He talks only, but we risk our lives...We are NOT motherless!" There is little doubt, according to Barker, about the significance of emotion in the "constitution of subjectivity and identity" [5]. Ka-Kui releases his anger in this scene seemingly to demonstrate that he is unreconciled to the meaningless sacrifice to his superior of the British Royal Police. He bellows that he and his Chinese colleagues are not motherless, which is a rarely-seen reminder to the British boss, either in the filmic text or in real life. Mother seems to connote motherland here. Although the superior he roars at is acted by a Chinese, it's not difficult to infer that the superior is a scapegoat, for the focus of Police Story is not any conflict between China and the UK [8]. Those who hide behind the scapegoat are the "ghosts from above", as dubbed in Cantonese by the Hong Kong people. The film shows unintentionally the thirst for getting rid of the status of being colonized.

The film Police Story III: Super Cop (1992) tells a story of Hong Kong Police and mainland police working together to fight against criminals. Ka-Kui is sent to Guangdong Province in mainland China, who undercovers with female police Chief Yang (acted by Michelle Yeoh), tactfully deals with several drug traffickers in Thailand and Malaysia, and finally successfully destroys the drug trafficking gang. What makes it different from other films in the series is the new character-Section Chief Yang a policewoman from the mainland. Ka-Kui works undercover as Lin Fusheng from Foshan City, while Chief Yang is his younger sister Huanv. The adding of the new character brings clashes between Hong Kong and the mainland allegorically. When returning to his hometown Foshan, Ka-Kui naturally tries out his not-so-perfect Mandarin. To his surprise, however, Chief Young speaks very fluent Cantonese back to him. Ka-kui experiences embarrassment for the first time in the film for his ignorance and imagination of the mainland. Foshan, as a matter of fact, is a Cantonese-speaking city in Guangdong Province. This kind of embarrassment continues to show up in the rest part of the film. As Hall argues, identities are not grounded in a "mere recovery of the past, which is waiting to be found, and which, when found, will secure our sense of ourselves into eternity", they are the names given to the different ways "we are positioned by, and position ourselves within, the narratives of the past" [6]. In Police Story III: Super Cop, the female Chief Yang and the male Ka-Kui are spokespersons for the mainland and Hong Kong respectively, constructing heroism of Hong Kong with gender differences. Although Ka-Kui sometimes needs to complete the arrangements made by the mainland police, he is more often than not the leader of the two.

The film New Police Story (2004), the first one in the Police Story series after the reunification of Hong Kong with China, is not very related to the previous productions of the series [9]. The word "new" in the film title suggests that it is a new story in the series, as well as that it is a story in new Hong Kong but not the colonial one before. In the film, Kwok-Wing's team colleagues die in harness one year ago partially because of Kwok-Wing's over confidence, so he has been dispirited since then. Nevertheless, people around him give him lots of support and encouragement, especially Zheng Xiaofeng (acted by Nicholas Tse) who pretends to be a policeman.

What differentiates New Police Story from the previous films in the series is that this film characterizes the youngsters of Hong Kong as the evil force. They are born in either wealthy or potent families (for example Joe, the leader of the five criminals, is the son of the Chief Superintendent of Hong Kong), whose weapons are imported from Europe. To release their dissatisfaction towards the society and hatred towards the 
police, they rob for excitement but not for money. This filmic text no longer imagines Hong Kong as a threatened city of international sinister gang, drug traffickers, or terrorist forces. Instead, the focus is now on the new force-the young generation of Hong Kong. It seems to suggest that Hong Kong needs to pay more attention to family issues rather than the double challenges from both home (mainland) and abroad. Thus seemingly the film consciously or unconsciously sends out the message that Hong Kong has returned home. Under the protection of the motherland, the biggest challenge is the cultivation of the next generation and the construction of the metropolitan Hong Kong rather than the threat and defiance from other evil countries.

\section{Plot and Conversation}

Putonghua became the official language of Hong Kong, though the native language is Cantonese [10].

In the book Cultural Studies: Theory and Practice by Barker, he mentions that globalization "provides the context for just such a crisis since it has increased the range of sources and resources available for identity construction" [5]. In a similar way, the fact that it provides undoubted and inevitable possibility for the reconstruction of Hong Kong people's identity that Hong Kong has changed from a British colonial city to a special administrative region. As Marchetti says, "as July 1997 comes and goes, and debate surrounding Hong Kong's political status intensifies, the film industry's place as an arena for the formation of identity and forum for speculation about Hong Kong's future also comes into question" [11], therefore the filmic texts record the trajectory of people's thinking. In addition to anxiety and fear, Hong Kong films show their subjective imagination of the culture, politics and even life style of mainland China. The film Police Story III: Super Cop, produced in 1992, is such an instance. Because the story is about the collaboration of Hong Kong police and mainland China counterparts to destroy drug traffickers, unlike other works, this film is everywhere in conflict and collision between the two cultures of Hong Kong and the mainland, and there is, of course, direct or indirect involvement in the theme of reunification. There is a meaningful dialogue at the end of the movie. After he and Chief Yang successfully capture the drug traffickers and get the stolen money back, Ka-Kui, sitting on the top of the train, says with pride: "the money belongs to our Hong Kong government." Chief Yang solemnly corrects him: "No, it belongs to all the Chinese people". The naughty Ka-Kui responds immediately: "let the Hong Kong government keep it for the time being. After 1997, we are all Chinese. It will be yours, too. OK?"

Yuan Shu points out that, unlike Bruce Lee's films, Jackie Chan's films do not focus on any colonial conflicts, but mold humorous characters and introduce comedy into Kung $\mathrm{Fu}$ films [8]. As a matter of fact, through various film languages, the film Police Story III: Super Cop reveals to the audience the complicated identity of Hong Kong before the reunification although the focus is not on the cultural conflict between
China and the UK. The opening of this movie shows such a scene: in the office a group of Hong Kong police are discussing how to deal with tough drug dealers. The camera tilts up to the portrait of Queen Elizabeth hanging on the wall. Then a Cantonese-speaking British white officer orders and assigns tasks. Then another white officer says in English: "the mission must be completed!" These juxtaposed shots clearly tell the audience that Hong Kong is still under the rule of the British Empire and its identity is still (post) colonial. There is such a comic turning point in "Super Police": when Ka-Kui, now an undercover who infiltrates the reform-through-labor camp in the mainland to rescue the rescued drug dealer Baoqiang (Panther) out to his hometown Foshan, Ka-Kui puzzlingly looks around the streets of Foshan, very unfamiliar with his fake role. Only when seeing a signpost, he successfully leads all to the big house passed down from generations before. The old mother in the made-up family is disguised by his colleague, Uncle Bill Wong, who dresses up as an old woman. Chief Yang is now his younger sister Hua Nv. When Baoqiang (Panther) points to the family photo on the wall and asks Ka-Kui who they are, the latter hesitates with no words uttered, bewildered and overwhelmed. With recourse to Stuart Hall's interpretation of the meaning of memory and history in the process of identity construction, it can be understood that the Hong Kong people, represented by Ka-Kui here, have been estranged to the culture of mainland China because of the erosion of British colonization for more than a century. They are now alienated from their own homeland, a rootless generation [1].

While playing the tentative role of integrating Hong Kong and mainland China, the film also gives an obvious account of stereotypical interpretation and even mockery of the mainland. The film also serves as a platform to express political doubts of the Hong Kong people.

There is such a group of montages in Police Story III: Super Cop. When Ka-Kui accepts the mission and says goodbye to his immediate superior, the shot immediately switches to two eye-catching National Flags of China at both sides of a driving car. Then what leaps into the audience's eyes is a large National Emblem of China, and below, five red Chinese characters "Serve the People" (Wei Renmin Fuwu). The film employs these objects to inform the audience that Ka-Kui is not in Hong Kong in the mainland now. What is the image of the mainland in the eyes of the Hong Kong people? The training ground is filled with slogans of "Be United, Alert, Earnest and Lively", and "Strive to Be a Pioneer, Anytime and Anywhere". The former one was once the motto of Chinese People's Anti-Japanese Military and Political College, while the second one reminds others the fighting spirit of the Chinese army. It seems to suggest that the socialist mainland is still stuck in the years right after the wars, and forms a sharp contrast with the capitalist Hong Kong which is more open, approachable, and focuses more on economic development. With the year 1997 approaching, the reunification was on the way. No matter how the Hong Kong people felt about this, be it excited, nervous, or resentful, there is no way to stop it. So when having to cooperate with the mainland China, Hong 
Kong also grasps the chance to smear the image of the counterpart in order to show its superiority. For example, in this film when asked if Ka-Kui has learned "Hard Qigong" (a hit-resistive exercise under the system of breathing exercise), he says, "of course not! It's so stupid to stand there to get beaten up".

If the cultural habit of pastiche has long been integrated into the collective unconsciousness of Hong Kong's culture [1], the changes in language/dialect embodied in this pastiche are reflected in the following changes if the three chosen films are compared. In the first movie, there is a combination of Cantonese, English, and mixed-up English and Cantonese in one expression; in the third and fifth films, Cantonese, English, and unstandardized Mandarin. This diversification highlights Hong Kong's image as a "melting pot of Asia" [11]. In New Police Story, a young criminal communicates with other characters in the film with fluent and standard Mandarin. It may be that he is from a mainland family that has migrated to and lived in Hong Kong, or that he has a preference for Mandarin. Or rather, in doing so it can bring some freshness to Hong Kong film. No matter what, it shows that Hong Kong gradually takes Mandarin as a matter of course after the reunification. From the dominating usage of Cantonese in Police Story, to Ka-Kui's attempt to use Mandarin to communicate with Chief Yang in Police Story III: Super Cop, then to the natural employment of Mandarin in New Police Story, the changes in the usage of different languages and the dialects show that the leading cultural values of Hong Kong are changing, even though this change is not necessarily pleasant or active. Jackie Chan's films once again tell the audience that Hong Kong is not really or totally westernized. It is just wandering and shuttling between the eastern and western cultures, surviving in a pastiche of various cultural phenomena.

\section{Urban Space and Architecture}

Although it cannot be guaranteed that the architects' designs will "secure liberty or rationality", the landscape and architecture of a city can still be read as a type of manifestation of its spatial identity [12]. When talking about Hong Kong's cultural identity, Ping-kwan Leung points out that apart from being different from China in terms of political and social characteristics, Hong Kong also develops "a cultural imagination and artistic forms to represent itself, which are both similar to and different from those in mainland China" [13]. After accepting the fate of returning to the socialist China, Hong Kong tries to balance its psychological loss by showing its advantage and superiority. In contrast, the film Police Story III: Super Cop shows the city of Guangzhou in this way: no landmark architecture of a modern city, but the figures of police soldiers standing upright on both sides of a gate, followed by the national emblem and the sign "serve the people" at the top of the gate. Hong Kong sticks to the stereotypical sarcasm of the military aspect of the mainland. The film's description of the environment of Foshan, another mainland city, shows the audience the dilapidated dusty streets, and people's shabby clothes, which is more like the situations in the 1970s, some 20 years before the 1990s. At the same time, the background music are the representative songs sung by two mainland singing artists_- "Red Star Shines on Me to the Battlefield" by Li Shuangjiang (this song, again, is the theme song of the film Shining Red Star with the theme of the Anti-Japanese War) and "My Motherland" by Guo Lanying - as if these cultural factors solely represent the mainland culture. The training ground where Ka-Kui competes with mainland public security officers is dilapidated, full of slogans and posters from the Great Leap to the Cultural Revolution. These scenes again, are symbols of the 1960s to the 1970s. The training ground can only be a fictional place and a projection of Hong Kong people's ideological imagination on the mainland. These images are very negative and are looked down upon by the people in Hong Kong. This imagination of backwardness not only shows Hong Kong's worry about being assimilated or encumbered by the mainland after the reunification, but also shows her psychological superiority to some extent. Without a real understanding and appreciation of the mainland culture, Jackie Chan's films can only wander away in imagination from the real Chinese culture.

If it could be said that "architecture cannot be separated from the spatial or ideological context in which it is produced", the architecture shown in the filmic text has a close relationship with the ideology of the film production team [14]. By comparing the quotations and displays of Hong Kong Architecture in the three films selected in this paper, it is not difficult to see the changes of Hong Kong identity in the past 10 years from another perspective. The opening scene of Police Story presents some wooden houses of the poor in Hong Kong built along the mountains. There are also luxurious private residences and large-scale shopping malls in the film, which shows the great gap between the rich and the poor in Hong Kong, a capitalist colonial city. As mentioned earlier in the paper, Police Story III: Super Cop depicts the imaginary picture of mainland China, and a dense forest in the outskirts of Thailand, which has been set up for the major drug dealers to meet and trade. In New Police Story, however, the national flag and the Hong Kong regional flag are shown within the frame many times between different scenes. A wide-angle shot shows the new landmarks of Hong Kong, including the Convention and Exhibition Center (HKCEC), Golden Bauhinia Square and the International Financial Center. The HKCEC is of special importance. The horizontal form of the architecture juts out over the harbor, in stark contrast to all the surrounding skyscrapers. At the end of the film, Ka-Kui's decisive battle with the criminal leader Joe, is waged in Hong Kong Investment Bank in the Exhibition Center and on the roof of the Exhibition Center. The Exhibition Center is a new landmark architecture for Hong Kong, to show the rid of British colonial rule and to witness its return to China. On July 1, 1997, the handover ceremony of Hong Kong was held there by the Chinese and British governments, announcing the establishment of the Hong Kong Special Administrative Region. Ten years later, a conference to celebrate the 10th anniversary of Hong Kong's return to 
China and the inauguration ceremony of the third government of the Hong Kong Special Administrative Region were also held there. It can be said that the HKCEC "witnessed the vicissitudes of Hong Kong's economic development and witnessed the extraordinary course of Hong Kong's return to China in the past 10 years"[15]. Hong Kong's tallest building, the International Financial Center, opened in 2003, is the world's third highest skyscraper, representing Hong Kong's position as an Asian financial center after its return to China. Space and architecture are of historical significance. If the disappearance of architecture can be seen "in relation to a recent cultural and political mood", then the "emergence" of new buildings is also inseparable from the political, cultural and economic development of a region [14]. After the reunification, the city logo of Hong Kong is not only the Bank of China Tower, but also the Convention and Exhibition Center and the International Financial Center, to name just a few. These new architectures are manifestation of Hong Kong's increasing recognition of Chinese identity.

\section{Reflection on Representation on Differences and Identity Recognition}

Jackie Chan's filmic products invite the audiences and scholars of Hong Kong to ponder over this question: should Hong Kong people identify with China or Hong Kong? The identity construction is under multiple influences of age, class, gender, race, nationality and so on. With the special historical experience of Hong Kong, the identity of Hong Kong people has become more complex and diverse.

Gayatri C. Spivak believes that the colony is in the "marginal" zone away from the center, and its dependence on the suzerain in politics, economy, culture and language imprints the word "subordinate" deeply on its cultural memory [1]. After the reunification, Hong Kong people's identity, which was originally fragile, is crumbling after being impacted by Chinese identity. The globalization of media has a great impact on the cultural identity of Hong Kong people. Although the local government "still creates Hong Kong consciousness" in many aspects, news media, television and film have been promoting the concept of Greater China in recent years [16]. Are Hong Kong people still British, or should they identify with Chinese identity or Hong Kong identity? Zhang Jing once points out that the movement of the black people and other ethnic minorities asking the question "who am I" is carried out by the whole society in a subversive way [2]. It can be said that over the years, especially in the last 10 years, Hong Kong people have been asking the question "who am I". In 1998 (the year right after the reunification) Jackie Chan produced a film under the title Who Am I, which is about a secret agent (acted by Jackie Chan) who falls from an airplane into the African jungle and lose his memory and so keeps asking about his identity. This can also be seen as the confusion that Hong Kong people cry out through movies, which seems to have no definite answer [17]. Because of the special historical reasons, the city of Hong Kong grows and develops with a marginalized cultural temperament [1]. What's more complicated is that with the increasing promotion of Internet culture, the geographical boundaries of the world are falling apart, and everyone has the opportunity to become "global consumers" and "world citizens". In what direction will Hong Kong people go on the road of identity recognition? This is a question to be thought about by the Hong Kong people, the film industry and even the intellectual circles.

According to Wang Yuechuan, the period of "identity confirmation" in modern China includes three stages, namely, "breaking the old culture, old concepts and old system", "identity re-positioning and rewriting", and "new cultural identity confirmation" [1]. The writer of the paper believes that the three works of Jackie Chan selected here can roughly represent the three stages of Hong Kong people's identity recognition. Police Story was shot in the sensitive period of the signing the Sino-British Joint Declaration. The film does not present very clearly whether Hong Kong is under the British rule or whether Hong Kong has pondered on self-awareness, which only continues to acquiesce the established system and conception for the past few decades. Police Story III: Super Cop depicts Hong Kong's cooperation with mainland China, which reflects Hong Kong's (sub)conscious repositioning of its cultural identity. When it comes to the time of production of New Police Story, it is the period when Hong Kong reclaiming her lost position, moving culturally away from the margin, and confirming their new cultural identity. Although this re-confirmation has not been carried out for a long time, Hong Kong has embarked on the journey of constructing its own cultural identity in the new multicultural era.

\section{Conclusion}

Identity has become a central topic of cultural studies since the 1990s. As a matter of fact, the concern about identity is about how people view each other. Its complexity refuses to give a single answer to the question of what identity is. In Today's circumstance, Hong Kong is still troubled by the issue of identity recognition, if not more than before. Although film "reproduces a virtual space", it has played, is playing and will continue to play an important role in the "formation of Hong Kong's specific culture" [13], Hong Kong films, "a special kind of commodity of Hong Kong", which are very active in the world film market, not only play their own roles in the film market, but also prompt the discussion of fundamental issues such as identity and self-determination [11]. As the products of an international film star, Jackie Chan's films are even more so. Even if the revelation of cultural identity is unconscious, it deserves the attention and interpretation from both the audience and intellectuals.

\section{References}

[1] Wang, Yuechuan (1999). Literary Theory of Post Colonialism and New Historicism. Jinan: Shandong Education Press, 147, 140, 139, 54, 138, 148-149. 
[2] Zhang, Jing (2006). Status Identity-Idea, Attitude, Justification. Shanghai: Shanghai People's Publishing House, $37,45$.

[3] http://news.sina.com.cn/c/2007-05-28/090013092021.shtml

[4] https://www.imdb.com/name/nm0000329/?ref_=fn_al_nm_1

[5] Barker, Chris (2008). Cultural Studies: Theory and Practice, $3^{\text {rd }}$ ed. Sage Publications: London, 255, 222.

[6] Hall, Stuart (2003). "Cultural identity and diaspora", in Theorizing Diaspora: A Reader, Eds. Jana Evans Braziel and Anita Mannur. Malden: Blackwell Publishing Ltd, pp. 222-237.

[7] Mao, Sihui \& Guo Haixia (2000). "Patriarchy, racism and women existence: On Kingston's short Story 'No Name Woman"', in New Perspectives: Contemporary Literary \& Cultural Studies, Eds. Mao Sihui \& Fang Kairui. Guangzhou: South China University of Technology Press, pp. 83-96.

[8] Yuan, Shu (2005). "From Bruce Lee to Jackie Chan", Xu Jiansheng Trans., in World Cinema, Vol 1, pp. 4-19.

[9] Wen, Jianjian \& Liang Jianhua (2004). Biography of Jackie Chan. Wuhan: Hubei People's Press, 259.

[10] Jones, Carol A. G. (2015). Lost in China? - Law, Culture and Identity in Post-1997 Hong Kong. Cambridge University Press: Cambridge, 232.
[11] Marchetti, Gina (2000). "Buying American, consuming Hong Kong: Cultural commerce, fantasies of identity, and the cinema", in The Cinema of Hong Kong: History, Arts, Identity, Eds. Poshek $\mathrm{Fu}$ and David Desser. Cambridge: Cambridge University Press, pp. 289-313.

[12] Foucault, Michel (2004). "Space, power and knowledge", in The Cultural Studies Reader, $2^{\text {nd }}$ ed. Ed. Simon During. London: Routledge, pp. 134-141.

[13] Leung, Ping-kwan (2000). "Urban cinema and the cultural identity of Hong Kong", in The Cinema of Hong Kong: History, Arts, Identity, Eds. Poshek Fu and David Desser. Cambridge: Cambridge University Press, pp. 227-251.

[14] Abbas, Ackbar (2004). "Building on disappearance: Hong Kong architecture and colonial space", in The Cultural Studies Reader, $2^{\text {nd }}$ ed. Ed. Simon During. London: Routledge, pp. 146-166.

[15] http://www.gov.cn/jrzg/2007-07/06/content_675637.htm

[16] http://www.rthk.org.hk/mediadigest/20040915 76 120092.ht $\mathrm{ml}$.

[17] Chan, Jackie and Jeff Yang (1999). I Am Jackie Chan: My Life in Action. New York: Ballantine books. 